\title{
An unusual hip dislocation during tennis playing
}

\author{
Ismail Turkmen, Fatih Turkmensoy, Korhan Ozkan, Salih Soylemez, \\ Feyza Unlu Ozkan, Yalcin Turhan
}

\begin{abstract}
Introduction: Isolated traumatic posterior hip dislocation is seen as an extremely rare incident during sport activities. In this case report we aimed to present an isolated traumatic posterior hip dislocation of an amateur tennis player. Case Report: A 26-year-old female patient who was injured during playing tennis was brought to our orthopedic emergency unit and diagnosed with pure posterior hip dislocation. Her hip was immediately reduced under sedation which then a rehabilitation program was begun. Conclusion: Amateur people generally play tennis on cement floor which may result in hip dislocation, if slipped. To prevent dislocations and these kinds of extreme injuries non-slippery shoes and shock absorbable relatively soft surfaces to play must be preferred by the players.
\end{abstract}

Keywords: Pure traumatic hip dislocation, Tennis player

Ismail Turkmen¹, Fatih Turkmensoy ${ }^{1}$, Korhan Ozkan², Salih Soylemez ${ }^{1}$, Feyza Unlu Ozkan ${ }^{3}$, Yalcin Turhan ${ }^{4}$

Affiliations: ${ }^{1} \mathrm{MD}$, Istanbul Medeniyet University Goztepe Training and Research Hospital, Department of Orthopaedics and Traumatology, Istanbul, TURKEY; ${ }^{2}$ Ass. Prof, Istanbul Medeniyet University, Department of Orthopaedics and Traumatology, Istanbul, TURKEY; ${ }^{3} \mathrm{MD}$, Istanbul Fatih Sultan Mehmet Training and Research Hospital, Department of Pyscial Therapy and Rehabilitation. Istanbul, TURKEY; ${ }^{4} \mathrm{MD}$, Duzce State Hospital, Department of Orthopaedics and Traumatology, Duzce, TURKEY.

Corresponding Author: Ismail Turkmen, Istanbul Medeniyet University Goztepe Training and Research Hospital, Department of Orthopaedics and Traumatology 34732 Istanbul, Turkey; Ph: 00905304622107; Fax: 0090216-56640-00; Email: dr.ismailturkmen@gmail.com

Received: 11 April 2013

Accepted: 10 May 2013

Published: 01 October 2013
Turkmen I, Turkmensoy F, Ozkan K, Soylemez S, Ozkan FU, Turhan Y. An unusual hip dislocation during tennis playing. International Journal of Case Reports and Images 2013;4(10):532-535.

$* * * * * * * * *$

doi:10.5348/ijcri-2013-10-373-CR-2

\section{INTRODUCTION}

Acute traumatic hip dislocation is usually caused by traffic accidents as dashboard injuries. Although it happens with high energy trauma, also low energy traumas, which usually happens during sport activities, might very rarely, cause traumatic hip dislocation. In this report we aimed to present an isolated traumatic hip dislocation of an amateur tennis player and this is the first report of this kind of injury during tennis playing.

\section{CASE REPORT}

A 26-year-old amateur female tennis player was admitted to our orthopedic emergency unit with hip pain and limitation of hip motion in her left extremity. Clinical examination revealed that her left leg was shortened, flexed, adducted and at an internally rotated position.

The patient was playing tennis on a cement floor and while she was running to catch a ball she slipped on a leaf. Her legs had struddled and left leg was flexed and internally rotated. She fell down on the floor and felt an extreme pain over her hip.

Radiographs of the pelvis showed posterior dislocation of the hip without fracture of acetabulum or femoral head (Figures 1 and 2). Type 1 dislocation was diagnosed according to Thompson and Epstein classification. The dislocation was reduced immediately under conscious sedation (midazolam $5 \mathrm{mg}$ intravenous) after diagnosis. 


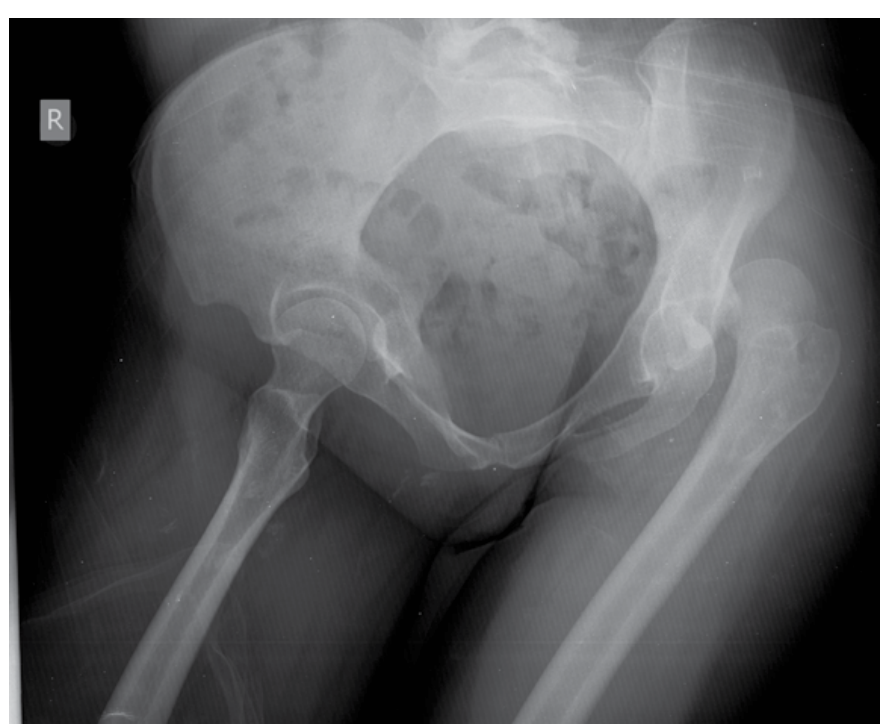

Figure 1: X-ray before reduction.

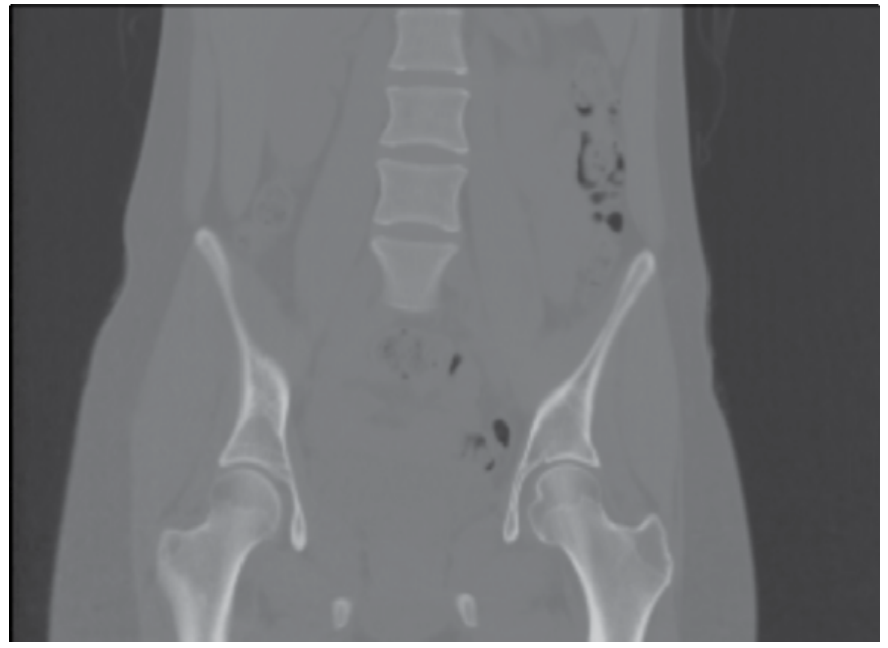

Figure 2: Postreduction coronal computed tomography scan showing no fracture.

Allis's maneuver was used for reduction. There was no sciatic nerve deficit before and after reduction. Skeletal traction was not applied. X-ray and magnetic resonance imaging (MRI) scan revealed concentric reduction of the hip joint (Figure 3). Indomethacin $75 \mathrm{mg}$ was begun for heterotopic ossification prophylaxis. Early mobilization allowed without weight bearing. Hip flexion over 90 degrees and internally rotation over 10 degrees were prohibited. She was followed-up for six weeks with gentle abductor and quadriceps strengthening exercises and weight bearing was allowed then. The patient was well six months after dislocation with normal activities.

\section{DISCUSSION}

Tennis is the one of the most popular sport in the world. Lower extremity ligament injuries, contusions, sprains, abrasions and upper extremity overuse injuries are frequently seen during playing tennis [1].

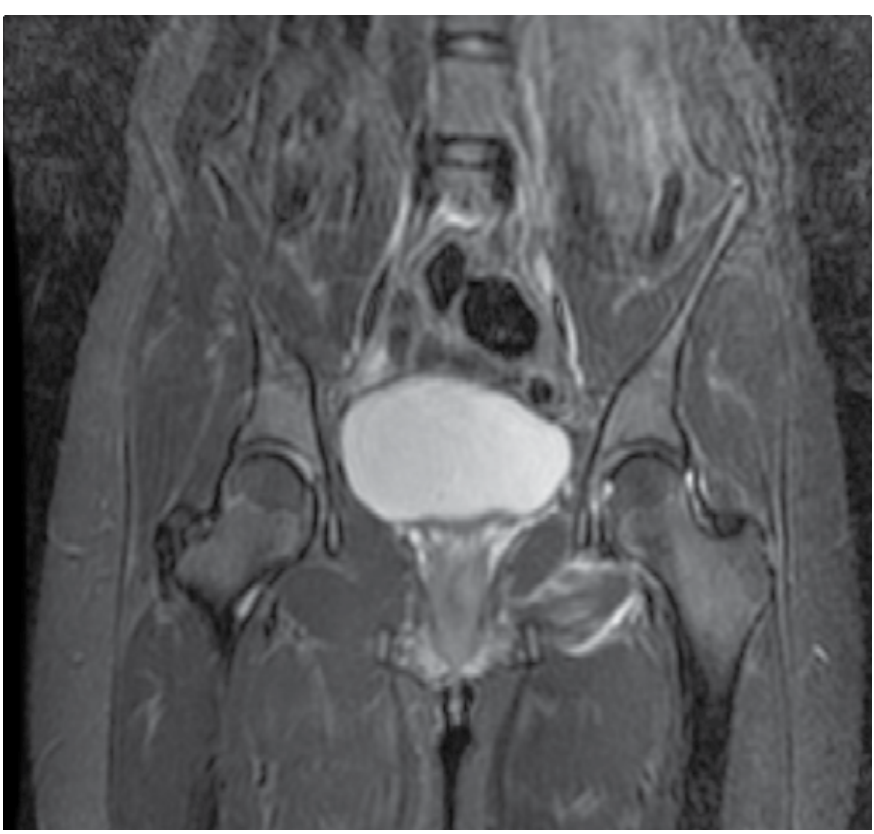

Figure 3: Postreduction magnetic resonance imaging scan showing piriformis edema in left hip.

Traumatic hip dislocation can be rarely seen in contact sports like soccer and rugby and hip dislocation without fracture of the femoral head and acetabulum is also notably rare. In this case report, there was no contact force and pure dislocation had been occurred without fracture.

In literature, traumatic hip dislocations in sports activity had been reported. But to our knowledge, there is no case reported that have a pure hip dislocation when playing non-contact sport like tennis. In English literature there are 21 traumatic hip dislocations with and without fracture in sports activity [2-8]. Among all these -6 rugby, 5 soccer, 2 futsal and one each water skiing, equestrian, gymnastic, jogging, skiing, biking, sledge, basketball player had traumatic hip dislocation- only five of them were pure dislocations.

Generally, mechanism of dislocation is that; when hip and knee is flexed and internally rotated, a powerful strike comes to the knee and it fractures posterior lip of the acetabulum. If the force is great enough, hip dislocates [9].

In management of traumatic hip dislocation early reduction is essential. Risk of avascular necrosis at femoral head increases as time goes on, especially over 6 hours [10]. If patient is not proper for general anesthesia for immediate reduction, sedation by midazolam or diazepam can be tried simply. Reduction maneuver should be done gently with an assistant who stabilize the pelvis otherwise femoral cartilage could be damaged and iatrogenic fractures can be seen. To avoid avascular necrosis, postreduction early mobilization and controlled weight bearing should be done in pure dislocations [11] Passive range of motion exercises and partially weight bearing can be done in following week after reduction. 
The third week patient can be allowed to walk with crutches and full weight bearing. After eight weeks of the dislocation light sport activities can be done and return to the competition can take at least six months [12].

\section{CONCLUSION}

Tennis is a well-known and widely played sport around the world. Usually minor injuries like shoulder rotator cuff tears, slap lesions, elbow problems or ligament injuries due to ankle sprain can be seen during playing tennis. Amateur people generally play tennis on cement floor which may result in hip dislocation, if slipped. To prevent dislocations and these kinds of extreme injuries non-slippery shoes and shock absorbable relatively soft surfaces to play must be preferred by the players.

$* * * * * * * * *$

\section{Author Contributions}

Ismail Turkmen - Substantial contributions to conception and design, Acquisition of data, Analysis and interpretation of data, Drafting the article, Revising it critically for important intellectual content, Final approval of the version to be published

Fatih Turkmensoy - Acquisition of data, Drafting the article, Revising it critically for important intellectual content, Final approval of the version to be published Korhan Ozkan - Acquisition of data, Drafting the article, Revising it critically for important intellectual content, Final approval of the version to be published

Salih Soylemez - Acquisition of data, Drafting the article, Revising it critically for important intellectual content, Final approval of the version to be published

Feyza Unlu Ozkan - Acquisition of data, Drafting the article, Revising it critically for important intellectual content, Final approval of the version to be published Yalcin Turhan - Acquisition of data, Drafting the article, Revising it critically for important intellectual content, Final approval of the version to be published

\section{Guarantor}

The corresponding author is the guarantor of submission.

\section{Conflict of Interest}

Authors declare no conflict of interest.

\section{Copyright}

(C) Ismail Turkmen et al. 2013; This article is distributed under the terms of Creative Commons attribution 3.0 License which permits unrestricted use, distribution and reproduction in any means provided the original authors and original publisher are properly credited. (Please see www.ijcasereportsandimages.com/copyright-policy.php for more information.)

\section{REFERENCES}

1. Bylak J, Hutchinson MR. Common sports injuries in young tennis players. Sports Med 1998 Aug;26(2):11932.

2. Giannoudis PV, Zelle BA, Kamath RP. Posterior Fracture-Dislocation of the Hip in Sports. European Journal of Trauma 2003 Dec;29(6):399-2.

3. Schuh A, Doleschal S, Schmickal T. Anterior Hip Dislocation in a Football Player: A Case Report. Case Report Med 2009;2009:363461.

4. Yates C, Bandy WD, Blasier RD. Traumatic dislocation of the hip in a high school football player. Phys Ther 2008 Jun;88(6):780-8.

5. Venkatachalam S, Heidari N, Greer T. Traumatic fracture-dislocation of the hip following rugby tackle: a case report. Sports Med Arthrosc Rehabil Ther Technol 2009 Dec 15;1:28.

6. Giza E, Mithöfer K, Matthews H, Vrahas M. Hip fracture-dislocation in football: a report of two cases and review of the literature. Br J Sports Med 2004 Aug;38(4):E17.

7. Yasin FN, Singh VA. Can posterior hip fracturedislocation occur in indoor football (futsal)? A report of two cases. BMJ Case Rep 2009;2009. pii: bcr12.2008.1317.

8. Nahas RM, Netto E, Chikude T, Ikemoto R. Traumatic hip fracture-dislocation in soccer: a case report. Rev Bras Med Esporte 2007 Jul;13(4).

9. Epstein HC. Traumatic dislocations of the hip. Clin Orthop Relat Res 1973;(92):116-42.

10. Hougaard K, Thomsen PB. Traumatic posterior dislocation of the hip--prognostic factors influencing the incidence of avascular necrosis of the femoral head. Arch Orthop Trauma Surg 1986;106(1):32-5.

11. Amihood S. Posterior dislocation of the hip. Clinical observations and review of literature. S Afr Med J 1974 May 18;48(24):1029-32.

12. Collins J, Trulock S, Chao DJ. Field management and rehabilitation of an acute posterior hip dislocation in a professional football player. Professional Football Athletic Trainer 2001;19:1-3. 
Access full text article on other devices

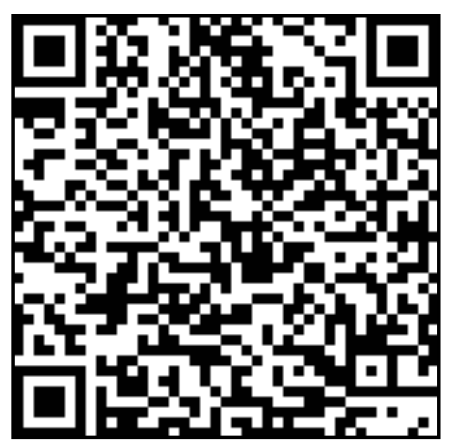

Access PDF of article on other devices

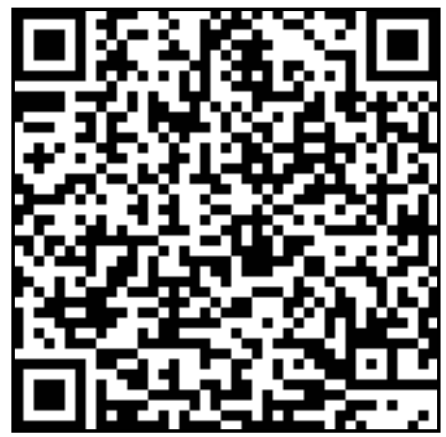

